\title{
Managing the patient with osteogenesis imperfecta: a multidisciplinary approach
}

This article was published in the following Dove Press journal:

Journal of Multidisciplinary Healthcare

4 April 2017

Number of times this article has been viewed

\section{Caroline Marr ${ }^{1, *}$ \\ Alison Seasman ${ }^{1, *}$ \\ Nick Bishop ${ }^{2}$ \\ 'Metabolic Bone Disease Team, ${ }^{2}$ Academic Unit of Child Health, Department of Human Metabolism, University of Sheffield, Sheffield Children's NHS Foundation Trust, Sheffield, UK}

*These authors contributed equally to this work

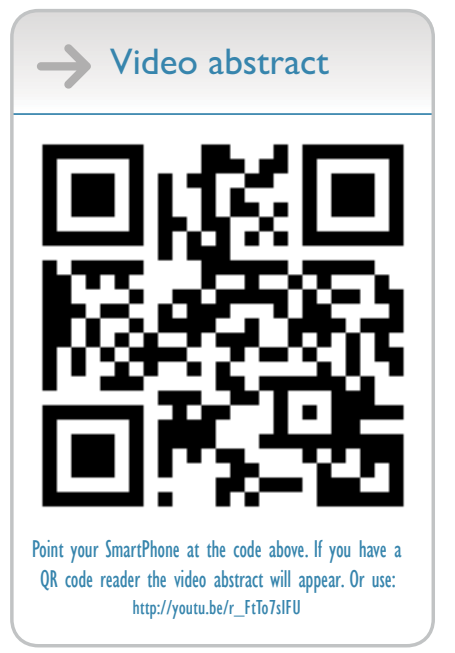

Correspondence: Caroline Marr Metabolic Bone Disease Team, Sheffield Children's NHS Foundation Trust, Western Bank, Sheffield, South Yorkshire SIO 2TH, UK

Tel +44 II 42267890

Fax +44 II4 2267832

Email Caroline.Marr@sch.nhs.uk
Abstract: Osteogenesis imperfecta (OI) is a heterogeneous heritable connective tissue disorder characterized by low bone density. The type and severity of OI are variable. The primary manifestations are fractures, bone deformity, and bone pain, resulting in reduced mobility and function to complete everyday tasks. OI affects not only the physical but also the social and emotional well-being of children, young people, and their families. As such, medical, surgical, and allied health professionals' assessments all play a role in the management of these children. The multidisciplinary approach to the treatment of children and young people living with OI seeks to provide well-coordinated, comprehensive assessments, and interventions that place the child and family at the very center of their care. The coordinated efforts of a multidisciplinary team can support children with OI to fulfill their potential, maximizing function, independence, and well-being.

Keywords: physical therapy, occupational therapy, bisphosphonates, nursing, psychology, pediatrics

\section{Introduction}

\section{Evolution of the multidisciplinary team}

Multidisciplinary team (MDT) management of complex, chronic diseases is an accepted part of clinical practice. In respect of the Metabolic Bone Disease Service at Sheffield Children's Hospital, the MDT approach began with the appointment of the UK's first consultant in pediatric metabolic bone disease in October 1998, with the MDT commencing its work early in 1999. The original team comprised the consultant, a full-time clinical nurse specialist (CNS), a half-time physical therapist and a full-time occupational therapist. The original expectation was that the service would grow from its original caseload of $\sim 25$ patients to 125 patients by the end of 5 years and then plateau. In 2016, 17 years after the team's inception, the caseload is $~ 500$ patients, more than half of whom have osteogenesis imperfecta (OI). In 2011, Sheffield was one of four centers designated by NHS England to deliver a highly specialized service (HSS) for severe, complex, and atypical pediatric OI. Sheffield sees $\sim 110$ of the 280 patients within this designated service. The size and scope of the MDT have increased steadily, adding psychology, social work, dentistry, and dietetics to the core services. The extended MDT meetings include orthopedic, spine, and neurosurgery as well as specialized skeletal radiology and genetics consultant input.

This review provides information on the assessment and management of children and young adults with OI. It aims to demonstrate how a specialist and an MDT are 
integral to providing a high-quality service that focuses not only on the patient's condition but also on the broader determinants of health and the priorities of care as directed by the children and their family.

\section{OI}

OI, often referred to as brittle bone disease, is a rare bone disorder characterized by bone fragility (fracturing with little-to-no trauma), short stature, long bone deformities, bone pain, low muscle mass, persistently blue sclera (in some), and hypermobility. ${ }^{1}$ The prevalence of $\mathrm{OI}$ is estimated at 1 in 10,000 new births. ${ }^{2}$ OI is described as a collagen disorder with most causative genetic mutations disrupting collagen biosynthesis. ${ }^{3}$ It can be inherited (autosomal dominant/autosomal recessive) or occur spontaneously (de novo/mosaic mutation) and is a condition with wide variability in phenotypic expression. ${ }^{4,5}$ Classification of OI follows on from the seminal work of Sillence et $\mathrm{al}^{6}$ in 1979 in which they classified OI into the following four distinct types: type 1 (mild), type 2 (lethal), type 3 (severe with progressive deformity), and type 4 (moderately severe). These four types are most often described in the literature and are attributed to the involvement of the pro-alpha-1 and pro-alpha-2 polypeptide chains of type one collagen (Table 1). 5,7

\section{Medical management Physician}

The physician is often the first point of contact for referrals of patients with OI. The initial role of the physician is to correctly identify OI and exclude other metabolic bone diseases resulting in bone fragility (the commonest reason for referral) such as idiopathic juvenile osteoporosis, hypophosphatasia, and other rare conditions. Assessment in the clinic should ideally be multidisciplinary with the nurse, physical therapist, and occupational therapist in attendance, allowing each team member to make an appropriate contribution. The physician should then ensure that the correct baseline investigations are undertaken and a management plan put in place. The predominant pharmacological interventions are analgesics and bone-targeting treatments such as bisphosphonates. Other medical problems consequent on immobility, such as constipation, will also require appropriate management.

Decisions on bisphosphonate initiation take into account the severity of the patients' condition, their age, and ability to manage either oral or intravenous administration. The decision regarding the type of bisphosphonate is made with parents, and dose frequency is initially 3 months for intravenous therapy (either pamidronate or zoledronic acid) and weekly for risedronate, given orally; children receiving oral bisphosphonates are seen every 6 months. Modification of dose is made on an individual basis, according to the response to treatment. Where patients prefer, some or all of the infusions can be given closer to home, but monitoring is undertaken in Sheffield.

Bisphosphonates are known to increase bone mass, improve vertebral size and shape, and in some studies have reduced the frequency of fractures. ${ }^{89}$ The efficacy of bisphosphonates in reducing fracture frequency may reflect the extent to which the increase in bone mass and improved bone architecture consequent on their use can offset the altered material properties of the bone tissue itself. There are anecdotal reports that bisphosphonates reduce bone pain, and certainly a consistent report from patients under our care is that they "slow down" and "ache more" when their next course of treatment is due.

The duration of bisphosphonate therapy and the titration of dose against either measurements of bone mass or bone turnover markers or the appearance of the vertebrae remain the subject of debate. There is considerable variation in practice between individual units, reflecting the uncertainty that exists and the lack of clear evidence to support any single specific approach.

New treatments using agents already in clinical use in postmenopausal and glucocorticoid-induced osteoporosis are finding their way into clinical trials of OI. A trial of denosumab in children started in Spring 2015, and a trial of parathyroid hormone (essentially ineffective) in adults with OI has also been reported. Other treatments are in development, and it is likely that further research will be needed to assess the impact and cost-effectiveness of these treatments compared to the existing approaches.

\section{Orthopedic surgeon}

Fracture management is the mainstay of orthopedic intervention in children and young adults with OI. ${ }^{10}$ Fracture management includes the stabilization of acute fractures (generally managed by local teams, although more complex fractures may warrant transfer to Sheffield Children's NHS Foundation Trust ( $\mathrm{SCH}$ ) for specialist care) and/or the prophylactic correction of deformity to reduce fracture risk. ${ }^{11}$

In our experience, corrective surgery can support ambulation by improving range of movement (eg, in the correction of coxa vara) and establishing better joint congruence through lower limb alignment. Similar outcomes are reported by the literature. ${ }^{12,13}$ Intramedullary rodding, using either nontelescopic rods (Rush rods, Kirschner wires) or telescopic rods (Sheffield rods, Fassier-Duval rods), is used for this 
Table I Ol genotypes and phenotypes

\begin{tabular}{|c|c|c|}
\hline Gene & Protein/area & Phenotype(s) \\
\hline & Collagen molecule & \\
\hline \multirow[t]{3}{*}{ COLIAI } & COLIAI & Mild-lethal $\mathrm{Ol}^{52}$ \\
\hline & & High bone mass in C-propeptide cleavage site defects ${ }^{53}$ \\
\hline & & Caffey disease with defect at, p.ArgI014Cys ${ }^{54}$ \\
\hline \multirow[t]{3}{*}{ COLIA2 } & COLIA2 & Mild-lethal $\mathrm{Ol}^{52}$ \\
\hline & & High bone mass in C-propeptide cleavage site defects ${ }^{53}$ \\
\hline & Type I collagen folding & \\
\hline PPIB & Cyclophilin B & Moderate-lethal $\mathrm{OI}^{55}$ \\
\hline LEPREI & $\mathrm{P} 3 \mathrm{H}$ & Severe-lethal $\mathrm{OI}^{56}$ \\
\hline \multirow[t]{2}{*}{ CRTAP } & CRTAP & Severe-lethal OI, ${ }^{59}$ Cole-Carpenter features ${ }^{59,81}$ \\
\hline & Collagen stability & \\
\hline \multirow[t]{2}{*}{ FKBPIO } & FKBP65; 65kD FK506-binding protein & Moderate-severe OI, Bruck syndrome (OI with contractures), ${ }^{59}$ \\
\hline & & Kuskokwim syndrome (contractures alone) ${ }^{60}$ \\
\hline PLOD2 & LH2 & Bruck syndrome ${ }^{61}$ \\
\hline SERPINHI & HSP47 & Severe OI, pyloric stenosis, skin bullae, renal stones ${ }^{62}$ \\
\hline \multirow[t]{2}{*}{ SPARC } & SPARC; osteonectin & Notable sarcopenia ${ }^{63}$ \\
\hline & Collagen processing/cleavage & \\
\hline \multirow[t]{2}{*}{ BMPI } & BMP I; Tolloid & High bone mass, hyperosteoidosis ${ }^{64}$ \\
\hline & Wnt-signaling pathway & \\
\hline \multirow[t]{3}{*}{ WNTI } & Wingless-type MMTV integration site family, member I & $\begin{array}{l}\text { Homozygous - severe Ol; some have brain malformation, some have } \\
\text { autism and some have learning difficulties. }{ }^{65}\end{array}$ \\
\hline & & Heterozygous - early onset osteoporosis, normal growth ${ }^{66}$ \\
\hline & Mineralization regulation & \\
\hline SERPINFI & PEDF & $\begin{array}{l}\text { Slowly progressively worsening } \mathrm{Ol} \text {, osteoid mineralization defect without } \\
\text { endochondral defect }{ }^{67}\end{array}$ \\
\hline \multirow[t]{2}{*}{ IFITM5/BRIL } & IFITM5 or BRIL & $\begin{array}{l}\text { Severe OI, metaphyseal dysplasia and sclerosis, hypertrophic callus, } \\
\text { interosseous membrane calcification }\end{array}$ \\
\hline & Osteoblast lineage & \\
\hline \multirow[t]{2}{*}{ SP7/OSX } & Sp7; Osterix & Typical Ol features ${ }^{71}$ \\
\hline & ER related & \\
\hline P4HB & P4H; PDI & $\begin{array}{l}\text { Cole-Carpenter syndrome, craniosynostosis, ocular proptosis, } \\
\text { hydrocephalus }{ }^{72}\end{array}$ \\
\hline TMEM38B & TRIC-B & Severe osteopenia and limb fractures without vertebral fractures ${ }^{73}$ \\
\hline CREB3LI & OASIS & Severe OI, cardiac failure ${ }^{74}$ \\
\hline SEC24D & Component of COPII complex & $\begin{array}{l}\text { Cole-Carpenter syndrome, craniosynostosis, ocular proptosis, } \\
\text { hydrocephalus }^{75}\end{array}$ \\
\hline \multirow[t]{2}{*}{ SPARC } & SPARC & Fragility worsens with age: similar to SERPINFI defects ${ }^{63}$ \\
\hline & Golgi membrane & \\
\hline \multirow[t]{2}{*}{ MBTPS2 } & & X-linked disease ${ }^{76}$ \\
\hline & Linker enzyme deficiency & \\
\hline \multirow[t]{2}{*}{$X Y L T 2$} & XYLT2 & Vertebral fractures, cataracts, heart defects ${ }^{77}$ \\
\hline & Bone fragility, not clearly OI & \\
\hline NBAS & NBAS & $\begin{array}{l}\text { Early onset osteoporosis, recurrent acute liver failure, developmental } \\
\text { delay }{ }^{78}\end{array}$ \\
\hline \multirow[t]{2}{*}{$L R P 5 / 6$} & LPRP5/6 & Homozygous - osteoporosis pseudoglioma syndrome ${ }^{79}$ \\
\hline & & Heterozygous - osteoporosis and/or vitreoretinopathy $y^{80}$ \\
\hline PLS3 & PLS3 & X-linked early onset severe osteoporosis without other OI features ${ }^{66}$ \\
\hline
\end{tabular}

Abbreviations: OI, osteogenesis imperfecta; ER, endoplasmic reticulum.

procedure. The benefit of one over another is subject to much debate. ${ }^{14-18}$ However, there is general consensus that telescopic rods are preferable for rodding the lower limbs of a growing child; a telescopic rod has greater longevity, thus reducing the number of surgeries required.

Orthopedic intervention is also required in the management of leg length discrepancy. Leg length discrepancies, associated with recurrent fractures and/or lower limb deformity, can impair function, increase back pain, and influence scoliosis progression. It is best practice to correct any leg length discrepancy as a preventative measure, be this with orthotics or orthopedic intervention (epiphysiodesis), to guide growth. Occasionally, the application of an Ilizarov frame is required to correct deformities and/or stabilize 
fractures, although this is not a procedure we see often in Sheffield. ${ }^{19,20}$

Spinal complications, including kyphosis, scoliosis, spondylosis, and spondylolisthesis, are common problems in children and young adults with OI and require regular monitoring to enable timely referral to an orthopedic spinal service. ${ }^{21}$ Management includes exercise, bracing, and surgery, although the best course of treatment continues to be debated. ${ }^{22,23}$ Any patient undergoing surgery would be reviewed by experienced anesthetic staff and further investigations determined based on their assessment. Pulmonary function is assessed prior to scoliosis surgery, but not prior to routine surgery for osteotomy and rodding.

\section{Neurosurgeon}

Hydrocephalus can occur early, even in those infants where the sutures have not fused. Regular measurement of head circumference should be undertaken in infants with OI. Clinical features of hydrocephalus are the same as those seen in those without OI - vomiting, lethargy, and headache with increased head circumference; "sun-setting" of the eyes; dilatation of scalp veins; and sutural diastasis. Diastasis due to hydrocephalus can be difficult to distinguish from poor skull vault mineralization in infants with severe OI. Hydrocephalus can also occur later due to herniation of the cerebellar tonsils.

Basilar invagination (BI) presents later in childhood; it can cause significant neurological difficulties and may be difficult to identify. The common signs are headache, nausea, lower cranial nerve dysfunction, paresthesia, ataxia, and nystagmus. It is radiologically evident on lateral skull radiographs as a progressive upward advance of the odontoid peg. Cord signal change on MRI indicates impending or existing cord damage. $\mathrm{BI}$ is very rare in mild $\mathrm{OI}$; our current practice is to perform foramen magnum-centered radiographs annually in moderately and severely affected patients to assess the relationship of the odontoid peg with the skull base and only investigate in mild cases where clinical signs are suggestive. Where concern over BI persists, MRI scans are also undertaken annually.

\section{CNS}

The main role of CNS is to coordinate patient care, ensuring that the services provided meet the unique needs of an individual and his or her family. ${ }^{24}$ CNS provides a crucial element of support, facilitating the admission process and liaising with patients, families, and other services in respect of broader care-related issues.
The CNS works closely with the therapy staff to provide handling and feeding support during early years. They coordinate dental appointments with treatment admissions with our associated specialist dental hospital in order to maximize proper dental care. As a child moves toward adolescence, the CNS drives the transition pathway. In Sheffield, we run monthly adolescent clinics for young people older than 12 years. The CNSs are integral to delivery of this program, which aims to not only help young people gain the knowledge and skills to manage their OI but also help them feel happier and more confident about the move to adult services. We have established close links with our adult partners at the Northern General Hospital in Sheffield but will also refer to other centers with expertise in the management of OI. Transition clinics run quarterly with both the pediatric and visiting adult consultants. Our adult partners offer a clinic dedicated to the needs of young people with OI, ensuring continuity of care and support.

CNSs also play a key role in the education of patients and families and provide support to ward staff and students. Where agreed with parents, the CNSs provide education to schools. CNSs ensure that written advice and recommendations are pertinent to the needs of the child. As a team, we work in collaboration with the Brittle Bone Society and the Paediatric Osteogenesis Imperfecta National Team (POINT) to provide support and trusted advice and information across services. Patients, families, carers, and local health professionals are encouraged to use these resources.

\section{Therapeutic strategies}

The literature surrounding therapy interventions, including physical therapy and occupational therapy, recognizes the importance each specialty has in enhancing function and independence for children with OI. ${ }^{25,26}$ The long-term goal is that children live independently and develop the life skills to enable them to direct their own care. ${ }^{21}$

Assessment and intervention at $\mathrm{SCH}$ includes inpatient, outpatient, and intensive therapy sessions. As outpatients, children are reviewed at least once a year in Sheffield or for those under the auspices of the HSS, in outreach clinics across the north of England; inpatients are reviewed at each admission. Community visits to home and school are undertaken across the region. Intensive therapy sessions involve a 5-day admission to $\mathrm{SCH}$ where children are seen two-to-three times daily.

Outcome measures are used in all of these settings. The Brief Assessment of Motor Function (BAMF) and the OI Pediatric Specific Quality of Life Questionnaire (OI qual) 
have been found to be valid and reliable..$^{27,28}$ In addition to ease of application, both of these outcome measures are useful tools in the clinical setting. The Gross Motor Function Measure (GMFM), reliable in OI, has been used with some success. However, as with many outcome measures, difficulties can arise with more severe patients. ${ }^{29} \mathrm{At} \mathrm{SCH}$, the Bayley Scales of Infant and Toddler Development, Movement Assessment Battery for Children and the Detailed Assessment of Speed of Handwriting (DASH) have been used in assessment and treatment planning. Although not valid or reliable in the OI population, these outcome measures have proven valuable in supporting a child's needs. ${ }^{30-32}$

Physical therapy and occupational therapy interventions include muscle strengthening; prevention of joint contractures; prevention of malalignment; improvement in function, including personal activities for daily living; transfers and ambulation; and modification and graded performance of everyday tasks. ${ }^{25,33,34}$ The therapy team supports children with OI to overcome the many obstacles to independent living, encouraging and respecting their individual problem-solving approaches.

\section{Occupational therapy and physical therapy Babies and toddlers}

In infants, positioning, handling, and transportation require considerable therapy input. ${ }^{35}$ Therapy ensures appropriate handling and support to minimize fracture risk, promote good alignment, and prevent worsening of deformities. In Sheffield, it is our practice to handle severe OI babies in supine, increasing their angle of incline over the first 2 years of life. The benefits of this approach are yet to be demonstrated in prospective longitudinal studies. However, clinical experience suggests that by handling severe OI babies in this way, their risk of crush fractures, kyphosis, and/or scoliosis is reduced. Complications associated with prolonged supine positioning, such as brachycephaly and plagiocephaly, can be addressed by establishing a routine with parents/carers that encourages frequent head turns and side and, when appropriate, prone lying. The provision of fabric rolls, wedges, and "book ends" (fabricated from splinting material) to maintain these positions can be key in ensuring the success of the routine. The cephalic index is measured at each admission in the first year of life to monitor brachycephaly and plagiocephaly. To promote cognitive development, parents/carers are encouraged to stimulate their baby through play; therapists offer advice on appropriate toys and activities. Parallel to this, the support of a clinical psychologist to track a baby's development ensures timely onward referral to specialist child development services as required.

Parents/carers are shown how to lift their baby for transportation, nappy changing, bathing, and dressing. Car seats that are "lay flat" or have a maximum recline are recommended. Prams should have a "lay flat" option, preferably with wheeled suspension. Bathing is recommended in a standard baby bath padded with a thick towel or foam support; the shallow water provides just enough buoyancy to encourage movement and kicking of the lower limbs. Clothing should minimize the pushing and pulling of limbs; items that open out fully along the torso, arms, and legs are preferable. Lightweight cotton clothing is recommended as synthetic fabric can exacerbate sweating, a common feature in this patient group.

We experience that toddlers, even with the mildest forms of OI, may have some delay in reaching key motor milestones, owing to hypermobility and/or recurrent fractures. Therapists facilitate the acquisition of gross motor skills progressively through play, the use of specialist equipment and functional tasks. Strategies focus on improving functional ability and developing self-care and independence skills. Toddlers are supported to first develop gross motor skills such as sitting and reaching and then progress to toileting, washing, dressing, and feeding. Despite careful assessment and intervention, planning, anxiety and fear of fracture, and movement can potentially create a barrier to the attainment of motor skills. Young children who experience recurrent fractures and/or surgery often delay in developing self-care tasks such as toileting; toddlers often resort to nappies when recovering from fracture/surgery. Consequently, acquisition of self-care skills may take longer than that in the general population. For more severely affected children, independence can be achieved with perseverance and the use of modified/specialized equipment; standard products are often too big, limiting comfort, stability, and accessibility.

Standing frames are not routinely used by the Metabolic Bone Team at SCH; they are not well tolerated due to bowing deformities and risk of fracture. Rather, therapists consider manual facilitation, regular stretches of muscle groups at risk of shortening (hip flexors/Achilles tendon), exercises that promote gross motor skills and improve strength and stability, appropriate walking aids such as the Kingcraft walker (developed in Sheffield), orthoses to support foot posture, and appropriate individualized wheelchair provision.

At $\mathrm{SCH}$, we consider wheelchair provision as early as 18 months old, commensurate with developmental milestones for ambulation. Consequently, children are supported and 
encouraged to explore their environment, facilitating cognitive development in line with their peers. For some, this may be a short-term intervention, with ambulation the long-term goal, especially in the more mildly affected individuals. For more severely affected children, the wheelchair is often their main form of mobility. Lightweight, "active user" wheelchairs such as the Panthera Micro maximize independent mobility for younger children; an abducted frame will support independent transfers. Young children should be provided with appropriate sized wheelchairs and not wheelchairs "to grow into"; an oversized wheelchair not only impairs function but may also encourage/exacerbate deformity.

\section{Children}

Children acquire skills, make friends and develop a sense of meaning and purpose in life through participation. ${ }^{36}$ However, many children with OI struggle with "being safe and careful, reduced function, pain, fear, independence, and isolation". ${ }^{37}$ Consequently, they find participation at home, at school, and in the wider community difficult. To ensure inclusion is a reality for these children, therapists should consider the important principles of energy conservation, positioning, and joint protection in addition to mobility and environmental access. At SCH, the goals of childhood are to improve strength, stamina, and mobility; to progress self-care skills; and to have fun being active.

For those more severely affected children, short stature and bowing deformities make performing everyday tasks such as transfers, washing, and dressing problematic. Children with type V OI often struggle with restricted elbow range of movement owing to calcification of the interosseous membrane and dislocation/subluxation of the radial head. This can make activities such as hair washing/brushing and bottom wiping difficult. At home and school, the provision of aids and adaptations can help children achieve independence. While extensive structural changes may sometimes be required, for example, ground floor wet room facilities, other accessibility problems can be addressed with simple assistive devices, for example, bath seat, grab rail, and wide shallow steps. At school, children may need disabled toilet facilities for ease of access; facilities can include toilet handles and frames, transfer plinths, or the addition of toilet chairs such as the Heathfield potty chair. Simply rearranging classroom seating/furniture and equipment can improve access and support participation.

The importance of providing appropriate wheelchairs and seating should not be underestimated. ${ }^{38}$ Assessment considers joint protection and prevention of bony deformity in addition to postural alignment principles. Each wheelchair and seating system should meet individual needs and is dependent not only on the child's limitations but also on their environment and the context in which they live.${ }^{39}$ At SCH, primary schoolaged children are encouraged to use manual wheelchairs such as the Panthera Micro or Zippie Simba, to maintain activity levels and fitness.

Seating provisions range from simple anterior tilt cushions and foot boxes for the mildly affected children to chairs offering hi-lo, tilt-in-space options for children requiring higher levels of postural control and protection. Children who require high levels of postural control are also given regular stretches, for example of the hip flexors, to prevent joint contractures. Home exercise programs that promote strength, for example, of the abdominal/spinal muscles, fitness, and independence are also encouraged.

Regardless of severity, muscle weakness is a common complaint for those who have OI. Whether this weakness is indicative of OI or a result of the sedentary lifestyle often adopted by this patient group, it can impact upon a child's everyday life. ${ }^{40-42}$ Van brussel et $\mathrm{al}^{43}$ found that a supervised exercise training program (twice weekly for 12 weeks) can have a positive impact, not only on a child's strength but also on his or her exercise and maximal working capacity. While the delivery of such a program is often untenable in clinical practice, individualized exercise programs can be integrated into daily life with the support of local therapists, schools, and parents/carers. Often, the most successful exercises are those that are meaningful and target more than one outcome, for example, baking from a perching stool rather than a wheelchair to work toward standing. This "exercise" requires lower and upper limb strength, proprioception and balance, coordination, planning, and fine motor manipulation. Baking and similar functional tasks are often used as part of the intensive therapy sessions at $\mathrm{SCH}$; the importance of play and using fun activities as part of therapy should not be underestimated.

When devising an exercise program for a child with OI therapists, consider the mechanical strain and muscle force acting upon the bone, particularly in children with bony deformity and associated loss of joint range. Hydrotherapy can be effective in promoting strength and facilitating/maintaining range of movement, especially following orthopedic intervention. Hydrotherapy should always be used in conjunction with a land-based program, as weight bearing through bone is essential in promoting bone strength. ${ }^{44,45}$

Often children with OI are discouraged from participating in sport due to risk of fracture or decreased mobility. While 
sports that significantly increase forces through the spine (trampolining, sledging, horse riding) are not recommended, with reasonable adjustments and careful consideration of the environment, children can participate in many activities alongside their peers. Schools often require the support of the therapy team to include children with OI in physical education. Therapists advise on suitable activities, provide individual exercise plans and suggest equipment adaptations. They work with schools to encourage the child to build a positive relationship with sport and exercise.

Ligamentous laxity/hypermobility, a common feature of OI, can have a significant impact on participation. Hypermobility can be generalized or extreme at specific joints. ${ }^{46}$ Children with hypermobility can lack strength and stamina to perform gross and fine motor activities. The interventions include muscle strengthening, advice on pacing activities and provision of assistive devices such as pencil grips and lycra gloves. Children with hypermobility often complain of fatigue. Fatigue, which can be overwhelming, may also be related to bone pain and poor sleep patterns. Children with OI regularly complain of "overheating" at night time. Appropriate mattress provision, which reduces the heat transfer rate between the child and the support surface, is recommended.

\section{Adolescents}

Adolescence can be a challenging time for all, especially those with chronic health conditions. Maintaining a regular review of young adults in the appropriate setting such as an adolescent clinic is important. ${ }^{47}$ Therapists work collaboratively with CNS to encourage and support adolescents to take responsibility for function, adjustment and well-being in all domains of life. The transition program implemented by the Metabolic Bone Team at SCH supports this goal.

The move to secondary school and college can herald many functional challenges. For mildly affected adolescents, manual wheelchairs can provide a means of pacing activity throughout the school day. More severely affected adolescents will require a powered wheelchair with an elevating seat to access a larger school campus and promote independence in the wider community. In addition to mobility aids, students are supported to move independently around school with reasonable adjustments, for example, lift access, leaving lessons early, etc. As academic demands increase, it is important for young people to develop compensatory and/or adaptive strategies to allow them to fulfill their academic potential; consider dictation software, scribe, and extra time.

Specialist seating provision can be complex at the secondary level owing to multiple classroom uses. Students may be allocated one specialist chair with a hi-lo facility (eg, Neptune, Wombat, Vela Tango) to be shared across a variety of lessons; ergonomic and environmental assessment is hence a prerequisite to maximize function. Stool seating in science, design and technology, and art should be reviewed, as adolescents with OI often require a back support and education regarding good spinal posture; ligamentous laxity and muscle weakness can place increased demands on the spinal muscles to maintain normal joint alignment.

Hypermobility, muscle weakness, long bone deformity, and joint contractures, with the associated loss of movement, all continue to be problematic for adolescents with OI. In devising an exercise program, the interests of the patient are an important consideration. A number of adolescents at $\mathrm{SCH}$ have been keen to participate in mainstream fitness activities and sports as these can be enjoyed alongside peers. However, access can sometimes be difficult owing to both the physical environment and health and safety concerns. Therapists provide advice on appropriate adjustments. At SCH, we offer young adults living locally the opportunity to have supervised gym sessions with a therapist.

Throughout adolescence, young people living with OI are faced with situations that challenge them both physically and emotionally. Although therapists are key in supporting their needs, the coordinated efforts of the MDT, including psychology and social work, are integral to their care.

\section{Psychology}

Under the HSS for severe, complex and atypical pediatric $\mathrm{OI}$, at $\mathrm{SCH}$, the clinical psychologist would routinely see all new babies and their families within the first few months of life. Early support and intervention can enhance attachment and bonding using tools such as the Newborn Behavioral Observations Assessment. ${ }^{48}$

As children grow, they are faced not only with physical but also with social and emotional demands. Psychological well-being can be affected as children find themselves in unfamiliar and unwanted situations, resulting in distress, anger, sadness, and anxiety. Consequently, parents/carers may find it difficult to manage both their child's emotional response and their own reaction to their child's presentation. ${ }^{49}$ The clinical psychologist is able to offer general support in addition to targeted anxiety and behavioral management strategies to these families in need. Regular monitoring with each admission ensures timely onward referral to local services.

While children with OI have the same aspirations as other children and young people, they may need additional help to achieve their goals. They often report feeling isolated and may 
have feelings of being "different". Some may fear needles and/or operations and some may feel depressed or even fear early death. ${ }^{31,50}$ The clinical psychologist supports children with OI and their families with these issues, including the emotional consequences of living with chronic disease and the impact that they can have on their and their family's life. ${ }^{51}$ Balancing the care of a child who has OI with the needs of other family members can lead to fatigue, stress, and sadness. This may impact on the health and relationships of parents/ carers and siblings. By working closely with the broader team, the psychologist can identify children and families likely to be at increased risk of developing psychological difficulties in order to offer preventative intervention. This may be onward referrals to local Child and Adolescent Mental Health Service, telephone consultations or group or 1:1 consultations as appropriate.

In Sheffield, the clinical psychologist also takes a lead on cognitive assessment and monitoring when concerns regarding development are raised. In conjunction with assessments completed by other team members, developmental tracking enables timely onward referral to specialist child development services as required. A multiagency working with education, social care, and other services in-line with assessment enables adequate support to be implemented for children with additional learning needs.

In addition to working directly with children and families, the clinical psychologist can provide consultation to team members to ensure profession-specific interventions meet and are appropriate for the psychological needs of the children and their families.

\section{Speech and language therapists and dieticians}

Although specialties in their own right, speech, and language therapists (SALTs) and dieticians complement each other and play an important role in the management of children with OI.

Dieticians are experts in nutritional assessment and care. They can suggest dietary modifications and develop nutritional care plans to help babies and children develop a healthy lifestyle diet that supports optimal bone mass, develops muscle strength, and avoids obesity. The Sheffield team members encourage and support mothers to breast or bottle feed their OI babies. Nasogastric tube feeding and percutaneous endoscopic gastrostomy (PEG) are used only in extreme circumstances. The more severely affected babies can be poor feeders: they may have a weak sucking reflex, gastric reflux, or respiratory problems. ${ }^{50}$ There is also the added complication that mothers are advised to nurse their babies in a supine position. While this may sometimes be difficult, the SALT and the dietician assist by developing strategies to improve feeding. They work collaboratively to provide a balanced nutritional diet with a variety of food textures to reduce the likelihood of oral defensiveness.

Complications can arise for babies and children with OI owing to their small stature, difficulties in breathing and swallowing in the neonatal period (severe babies), limited mobility and low appetite (particularly at times of fracture/ surgery and for those children experiencing chronic pain). The dietician provides advice on the size and frequency of feeds to ensure that slow growth is not mistaken as a failure to thrive. Unlike other skeletal dysplasia such as achondroplasia, there are no disease-specific growth charts for babies with OI. In the very young adults, this can lead to inaccurate assessment of growth and weight gain, often leading to increased stress and anxiety for parents/carers.

Children and young adults with OI should be encouraged to eat a balanced diet that is low in fat, salt, and added sugar and contains a variety of vitamins and minerals. ${ }^{50}$ They often struggle with constipation, which can be attributed to short stature, inactivity, pelvic asymmetry, and dehydration. Some children avoid defecation away from home owing to practical difficulties and inconvenience. ${ }^{51} \mathrm{~A}$ high-fiber diet that includes plenty of water/fluids and physical activity can help alleviate this problem. This requires a coordinated treatment plan from the dietician, physiotherapist, occupational therapist, psychologist, pediatrician, and family.

Obesity is a risk in children and young adults with OI. In addition to the extra stress placed on the skeleton, obesity may interfere with rehabilitation and can lead to other health complications. Dieticians work at the primary health promotion level, educating children and families living with OI about high nutrient, low fat foods, and the importance of portion control. Working closely with the wider team, the dietician is able to calibrate diet to age, size, and levels of activity.

\section{Social worker}

Psychosocial assessment and intervention form part of the treatment plan for children with OI. There are many issues involved in caring for a person with OI that are not medical, for example, housing, education, funding for equipment, social support, and benefits. This is in addition to coping with and adjusting to living with a lifelong condition. Relevant information about psychosocial functioning is shared with the MDT as appropriate. This helps to ensure that the emotional and practical support the whole family needs is considered in planning. 
Following diagnosis, families can become stressed due to the complicated nature and lifelong effects of the condition. Social workers provide families with trusted information and resources to help them plan for and take care of their child. They partner with families to advocate for their child both in and out of the hospital. They provide essential support to access financial assistance, benefits, and charity claims and applications. Social workers ensure that families access all the benefits, charities or local authority resources for which they are eligible. This can include practical support such as local activities, flexible short breaks, direct payments, or holidays. Social workers aim to ensure that the social aspect of a family's life is impacted as little as possible by their child's medical diagnosis.

Social workers liaise with medical teams and other local authorities in the identification and response to child protection concerns. They support other members of the MDT in identifying and referring child protection concerns to the relevant departments. This is always alongside referrals for support when children and family are in need.

\section{Summary}

Management of children and young adults with OI is complex and challenging due to the heterogeneity both across and within the different types. There is no single intervention or plan that can meet the needs of all. Best practice requires the input of an MDT delivered within a setting of a pediatric bone unit. The focus of interventions should be not only on the condition but on the broader determinants of health as well. By working collaboratively, children and young adults with OI are supported to improve health and quality of life, family and social participation, and academic achievement. Within the MDT, mutual respect, communication and specialist skills are required to deliver a gold standard of care. With joint working patterns, the MDT shares knowledge and expertise, delivering holistic treatment plans. Feedback from patients indicates that the MDT approach facilitates and enhances a sense of partnership, friendship, and support for OI families.

\section{Practice points}

Bisphosphonates and surgical intervention, supported by therapeutic strategies, improve function and quality of life in children and young adults with OI.

- Best practice is achieved through working of MDT, delivered in a specialist pediatric bone center.

- Aims of treatment are to maximize function, independence, and well-being, providing the child and young adult with life skills to direct their own care.
- Accessing accurate information about the condition can be helpful in establishing working relationships. Patients, families, and those involved in the care of a child with OI should be encouraged to access the POINT leaflets and web-based information source supported by charities such as the Brittle Bone Society.

\section{Disclosure}

The authors report no conflicts of interest in this work.

\section{References}

1. Forlino A, Cabral WA, Barnes AM, Marini JC. New perspectives on osteogenesis imperfecta. Nat Rev Endocrinol. 2011;7(9):540-557.

2. Dogba MJ, Rauch F, Tre G, Glorieux FH, Bedos C. Shaping and managing the course of a child's disease: parental experiences with osteogenesis imperfecta. Disabil Health J. 2014;7(3):343-349.

3. Marini JC, Reich A, Smith SM. Osteogenesis imperfecta due to mutations in non-collagenous genes: lessons in the biology of bone formation. Curr Opin Pediatr. 2014;26(4):500-507.

4. Shapiro JR, Byers PH, Glorieux FH, Sponseller P. Osteogenesis Imperfecta: A Translational Approach to Brittle Bone Disease. Cambridge, MA: Academic Press; 2013.

5. Shaker JL, Albert C, Fritz J, Harris G. Recent developments in osteogenesis imperfecta. F1000Res. 2015;4(F1000 Faculty Rev):681.

6. Sillence D, Senn A, Danks D. Genetic heterogeneity in osteogenesis imperfecta. J Med Genet. 1979;16(2):101-116.

7. Marini JC, Blissett AR. New genes in bone development: what's new in osteogenesis imperfecta. J Clin Endocrinol Metab. 2013;98(8): 3095-3103.

8. Sakkers R, Kok D, Engelbert R, et al. Skeletal effects and functional outcome with olpadronate in children with osteogenesis imperfecta: a 2-year randomised placebo-controlled study. Lancet. 2004;363(9419):1427-1431.

9. Bishop N, Adami S, Ahmed SF, et al. Risedronate in children with osteogenesis imperfecta: a randomised, double-blind, placebo-controlled trial. Lancet. 2013;382(9902):1424-1432.

10. Rauch F, Glorieux FH. Osteogenesis imperfecta. Lancet. 2004; 363(9418):1377-1385.

11. Nicolaou N, Bowe JD, Wilkinson JM, Fernandes JA, Bell MJ. Use of the Sheffield Telescopic Intramedullary Rod System for the management of osteogenesis imperfecta: clinical outcomes at an average follow-up of nineteen years. J Bone Joint Surg Am. 2011;93(21):1994-2000.

12. Stockley I, Bell MJ, Sharrard WJ. The role of expanding intramedullary rods in osteogenesis imperfecta. J Bone Joint Surg Br. 1989;989(71-B):422-427.

13. Aarabi M, Rauch F, Hamdy RC, Fassier F. High prevalence of coxa vara in patients with severe osteogenesis imperfecta. J Pediatr Orthop. 2006;26(1):24-28.

14. El-Adl G, Khalil MA, Enan A, Mostafa MF, El-Lakkany MR. Telescoping versus non-telescoping rods in the treatment of osteogenesis imperfecta. Acta Orthop Belg. 2009;75(2):200-208.

15. Harrison W, Rankin K. Osteogenesis imperfecta in Zimbabwe: a comparison between treatment with intramedullary rods of fixed-length and self-expanding rods. J R Coll Surg Edinb. 1998;43(5):328-332.

16. Porat S, Heller E, Seidman DS, Meyer S. Functional results of operation in osteogenesis imperfecta: elongating and nonelongating rods. J Pediatr Orthop. 1991;11(2):200-203.

17. Mulpuri K, Joseph B. Intramedullary rodding in osteogenesis imperfecta. J Pediat Orthop. 2000;20(2):267-273.

18. Wilkinson J, Scott B, Clarke A, Bell M. Surgical stabilisation of the lower limb in osteogenesis imperfecta using the Sheffield Telescopic Intramedullary Rod System. J Bone Joint Surg Br. 1998;80(6): 999-1004. 
19. Saldanha K, Saleh M, Bell M, Fernandes J. Limb lengthening and correction of deformity in the lower limbs of children with osteogenesis imperfecta. J Bone Joint Surg Br. 2004;86(2):259-265.

20. Birke O, Davies N, Latimer M, Little DG, Bellemore M. Experience with the Fassier-Duval telescopic rod: first 24 consecutive cases with a minimum of 1-year follow-up. J Pediatr Orthop. 2011;31(4): 458-464.

21. Arundel P. Osteogenesis imperfecta. Paediatr Child Health. 2015; 25(12):574-579.

22. Karbowski A, Schwitalle M, Eckardt A. Skoliose bei Patienten mit Osteogenesis imperfecta: Eine bundesweite Querschnittstudie [Scoliosis in patients with osteogenesis imperfecta: a federal nation-wide cross-sectional study]. Z Orthop Ihre Grenzgeb. 1999;137(3):219-222. German.

23. Hanscom DA, Bloom BA. The spine in osteogenesis imperfecta. Orthop Clin North Am. 1988;19(2):449-458.

24. Bishop N. Osteogenesis imperfecta. Clin Rev Bone Miner Metab. 2004;2(1):19-35.

25. Binder H, Conway A, Hason S, et al. Comprehensive rehabilitation of the child with osteogenesis imperfecta. Am J Med Genet. 1993; 45(2):265-269.

26. Monti E, Mottes M, Fraschini P, et al. Current and emerging treatments for the management of osteogenesis imperfecta. Ther Clin Risk Manag. 2010;6:367.

27. Cintas HL, Siegel KL, Furst GP, Gerber LH. Brief assessment of motor function: reliability and concurrent validity of the Gross Motor Scale. Am J Phys Med Rehabil. 2003;82(1):33-41.

28. Hill CL, Baird WO, Walters SJ. Quality of life in children and adolescents with osteogenesis imperfecta: a qualitative interview based study. Health Qual Life Outcomes. 2014;12(1):1.

29. Ruck-Gibis J, Plotkin H, Hanley J, Wood-Dauphinee S. Reliability of the gross motor function measure for children with osteogenesis imperfecta. Pediatr Phys Ther. 2001;13(1):10-17.

30. Bayley N. Bayley Scales of Infant and Toddler Development. 3rd ed. San Antonio, TX: Pearson Education Limited; 2005.

31. Barnett A, Henderson SE, Sugden DA. Movement Assessment Battery for Children. 2nd ed. San Antonio, TX: Pearson Education Limited; 2007.

32. Barnett A, Henderson SE, Scheib B, Schulz J. Detailed Assessment of Speed of Handwriting (DASH). San Antonio, TX: Pearson Education Limited; 2007.

33. Biggin A, Munns CF. Osteogenesis imperfecta: diagnosis and treatment. Curr Osteoporos Rep. 2014;12(3):279-288.

34. Binder H, Conway A, Gerber L. Rehabilitation approaches to children with osteogenesis imperfecta: a ten-year experience. Arch Phys Med Rehabil. 1993;74(4):386-390.

35. Hill C, Hampshire D, Silverwood B, Bishop NJ. Recent advances in the management of osteogenesis imperfecta. Curr Paediatr. 2003; 13(2):151-157.

36. Anaby D, Korner-Bitensky N, Law M, Cormier I. Focus on participation for children and youth with disabilities: supporting therapy practice through a guided knowledge translation process. Br J Occup Ther. 2015;78(7):440-449.

37. Hill CL, Baird WO, Walters SJ. Quality of life in children and adolescents with osteogenesis imperfecta: a qualitative interview based study. Health Qual Life Outcomes. 2014;12(1):8.

38. Armstrong W, Borg J, Krizack M, et al. Guidelines on the Provision of Manual Wheelchairs in Less Resourced Settings. World Health Organization; 2008. Available from: http://apps.who.int/iris/bitstr eam/10665/43960/1/9789241547482_eng.pdf. Accessed November $18,2016$.

39. Kenny S, Gowran RJ. Outcome measures for wheelchair and seating provision: a critical appraisal. Br J Occup Ther. 2014;77(2):67-77.

40. Caudill A, Flanagan A, Hassani S, et al. Ankle strength and functional limitations in children and adolescents with type I osteogenesis imperfecta. Pediatr Phys Ther. 2010;22(3):288-295.
41. Takken T, Terlingen HC, Helders PJ, Pruijs H, van Der Ent CK, Engelbert RH. Cardiopulmonary fitness and muscle strength in patients with osteogenesis imperfecta type I. J Pediatr. 2004;145(6):813-818.

42. Graf A, Hassani S, Krzak J, et al. Gait characteristics and functional assessment of children with type I osteogenesis imperfecta. J Orthop Res. 2009;27(9):1182-1190.

43. Van Brussel M, Takken T, Uiterwaal CS, et al. Physical training in children with osteogenesis imperfecta. J Pediatr. 2008;152(1):111-116,116.e1.

44. Schönau E, Fricke O. Muscle and bone: a functional unit. Dtsch Arztebl. 2006;103(50):A3414-A3419.

45. Veilleux LN, Pouliot-Laforte A, Lemay M, Cheung MS, Glorieux FH, Rauch F. The functional muscle-bone unit in patients with osteogenesis imperfecta type I. Bone. 2015;79:52-57.

46. Bird HA. Joint hypermobility. Musculoskeletal Care. 2007;5(1):4-19.

47. Shapiro J, Germain-Lee E. Osteogenesis imperfecta: effecting the transition from adolescent to adult medical care. J Musculoskelet Neuronal Interact. 2012;12(1):24-27.

48. Nugent JK. Understanding Newborn Behavior \& Early Relationships: The Newborn Behavioral Observations (NBO) System Handbook. Baltimore, MD: Brookes Pub; 2007.

49. Jacobs K, Titman P, Edwards M. Bridging psychological and physical health care. Psychologist. 2012;25(3):190-193.

50. Glorieux F. In: Glorieaux F, editor. Guide to Osteogenesis Imperfecta for Pediatricians and Family Practice Physicians. Gaithersburg, MD: Osteogensis Imperfecta Foundation; 2007.

51. Duff AJ, Bryon M. Consultation with paediatric teams. Clin Child Psychol Psychiatry. 2005;10(1):102-111.

52. Forlino A, Marini JC. Osteogenesis imperfecta. Lancet. 2016; 387(10028):1657-1671

53. Lindahl K, Barnes AM, Fratzl-Zelman N, et al. COL1 C-propeptide cleavage site mutations cause high bone mass osteogenesis imperfecta. Hum Mutat. 2011;32(6):598-609.

54. Gensure RC, Makitie O, Barclay C, et al. A novel COL1A1 mutation in infantile cortical hyperostosis (Caffey disease) expands the spectrum of collagen-related disorders. J Clin Invest. 2005;115(5): 1250-1257.

55. van Dijk FS, Nesbitt IM, Zwikstra EH, et al. PPIB mutations cause severe osteogenesis imperfecta. Am J Hum Genet. 2009;85(4): 521-527.

56. Cabral WA, Chang W, Barnes AM, et al. Prolyl 3-hydroxylase 1 deficiency causes a recessive metabolic bone disorder resembling lethal/ severe osteogenesis imperfecta. Nat Genet. 2007;39(3):359-365.

57. Barnes AM, Chang W, Morello R, et al. Deficiency of cartilageassociated protein in recessive lethal osteogenesis imperfecta. $\mathrm{N} \mathrm{Engl}$ J Med. 2006;355(26):2757-2764.

58. Morello R, Bertin TK, Chen Y, et al. CRTAP is required for prolyl 3hydroxylation and mutations cause recessive osteogenesis imperfecta. Cell. 2006;127(2):291-304.

59. Schwarze U, Cundy T, Pyott SM, et al. Mutations in FKBP10, which result in Bruck syndrome and recessive forms of osteogenesis imperfecta, inhibit the hydroxylation of telopeptide lysines in bone collagen. Hum Mol Genet. 2013;22(1):1-17.

60. Barnes AM, Duncan G, Weis M, et al. Kuskokwim syndrome, a recessive congenital contracture disorder, extends the phenotype of FKBP10 mutations. Hum Mutat. 2013;34(9):1279-1288.

61. Ha-Vinh R, Alanay Y, Bank RA, et al. Phenotypic and molecular characterization of Bruck syndrome (osteogenesis imperfecta with contractures of the large joints) caused by a recessive mutation in PLOD2. Am J Med Genet A. 2004;131A(2):115-120.

62. Christiansen HE, Schwarze U, Pyott SM, et al. Homozygosity for a missense mutation in SERPINH1, which encodes the collagen chaperone protein HSP47, results in severe recessive osteogenesis imperfecta. Am J Hum Genet. 2010;86(3):389-398.

63. Mendoza-Londono R, Fahiminiya S, Majewski J, et al; Care4Rare Canada Consortium. Recessive osteogenesis imperfecta caused by missense mutations in SPARC. Am J Hum Genet. 2015;96(6):979-985. 
64. Hoyer-Kuhn H, Semler O, Schoenau E, Roschger P, Klaushofer K, Rauch F. Hyperosteoidosis and hypermineralization in the same bone: bone tissue analyses in a boy with a homozygous BMP1 mutation. Calcif Tissue Int. 2013;93(6):565-570.

65. Fahiminiya S, Majewski J, Mort J, Moffatt P, Glorieux FH, Rauch F. Mutations in WNT1 are a cause of osteogenesis imperfecta. $\mathrm{J} \mathrm{Med}$ Genet. 2013;50(5):345-348.

66. Keupp K, Beleggia F, Kayserili H, et al. Mutations in WNT1 cause different forms of bone fragility. Am J Hum Genet. 2013;92(4):565-574.

67. Becker J, Semler O, Gilissen C, et al. Exome sequencing identifies truncating mutations in human SERPINF1 in autosomal-recessive osteogenesis imperfecta. Am J Hum Genet. 2011;88(3):362-371.

68. Balasubramanian M, Parker MJ, Dalton A, et al. Genotype-phenotype study in type V osteogenesis imperfecta. Clin Dysmorphol. 2013;22(3):93-101.

69. Cho TJ, Lee KE, Lee SK, et al. A single recurrent mutation in the 5'-UTR of IFITM5 causes osteogenesis imperfecta type V. Am J Hum Genet. 2012;91(2):343-348.

70. Semler O, Garbes L, Keupp K, et al. A mutation in the 5'-UTR of IFITM5 creates an in-frame start codon and causes autosomal-dominant osteogenesis imperfecta type V with hyperplastic callus. Am J Hum Genet. 2012;91(2):349-357.

71. Lapunzina P, Aglan M, Temtamy S, et al. Identification of a frameshift mutation in Osterix in a patient with recessive osteogenesis imperfecta Am J Hum Genet. 2010;87(1):110-114.

72. Rauch F, Fahiminiya S, Majewski J, et al. Cole-Carpenter syndrome is caused by a heterozygous missense mutation in P4HB. Am J Hum Genet. 2015;96(3):425-431.
73. Shaheen R, Alazami AM, Alshammari MJ, et al. Study of autosomal recessive osteogenesis imperfecta in Arabia reveals a novel locus defined by TMEM38B mutation. J Med Genet. 2012;49(10):630-635.

74. Symoens S, Malfait F, D'Hondt S, et al. Deficiency for the ER-stress transducer OASIS causes severe recessive osteogenesis imperfecta in humans. Orphanet J Rare Dis. 2013;8:154.

75. Garbes L, Kim K, Riess A, et al. Mutations in SEC24D, encoding a component of the COPII machinery, cause a syndromic form of osteogenesis imperfecta. Am J Hum Genet. 2015;96(3):432-439.

76. Lindert U, Cabral WA, Ausavarat S, et al. MBTPS2 mutations cause defective regulated intramembrane proteolysis in X-linked osteogenesis imperfecta. Nat Commun. 2016;7:11920.

77. Munns CF, Fahiminiya S, Poudel N, et al. Homozygosity for frameshift mutations in XYLT2 result in a spondylo-ocular syndrome with bone fragility, cataracts, and hearing defects. Am J Hum Genet. 2015;96(6):971-978.

78. Capo-Chichi JM, Mehawej C, Delague V, et al. Neuroblastoma Amplified Sequence (NBAS) mutation in recurrent acute liver failure: confirmatory report in a sibship with very early onset, osteoporosis and developmental delay. Eur J Med Genet. 2015;58(12):637-641.

79. Gong Y, Slee RB, Fukai N, et al. LDL receptor-related protein 5 (LRP5) affects bone accrual and eye development. Cell. 2001;107(4):513-523.

80. Hartikka H, Makitie O, Mannikko M, et al. Heterozygous mutations in the LDL receptor-related protein 5 (LRP5) gene are associated with primary osteoporosis in children. J Bone Miner Res. 2005;20(5):783-789.

81. Balasubramanian M, Pollitt RC, Chandler KE, et al. CRTAP mutation in a patient with Cole-Carpenter syndrome. Am J Med Genet A. 2015;167A(3):587-591.
Journal of Multidisciplinary Healthcare

\section{Publish your work in this journal}

The Journal of Multidisciplinary Healthcare is an international, peerreviewed open-access journal that aims to represent and publish research in healthcare areas delivered by practitioners of different disciplines. This includes studies and reviews conducted by multidisciplinary teams as well as research which evaluates the results or conduct of such teams or health

\section{Dovepress}

care processes in general. The journal covers a very wide range of areas and welcomes submissions from practitioners at all levels, from all over the world The manuscript management system is completely online and includes a very quick and fair peer-review system. Visit http://www.dovepress.com/ testimonials.php to read real quotes from published authors. 